
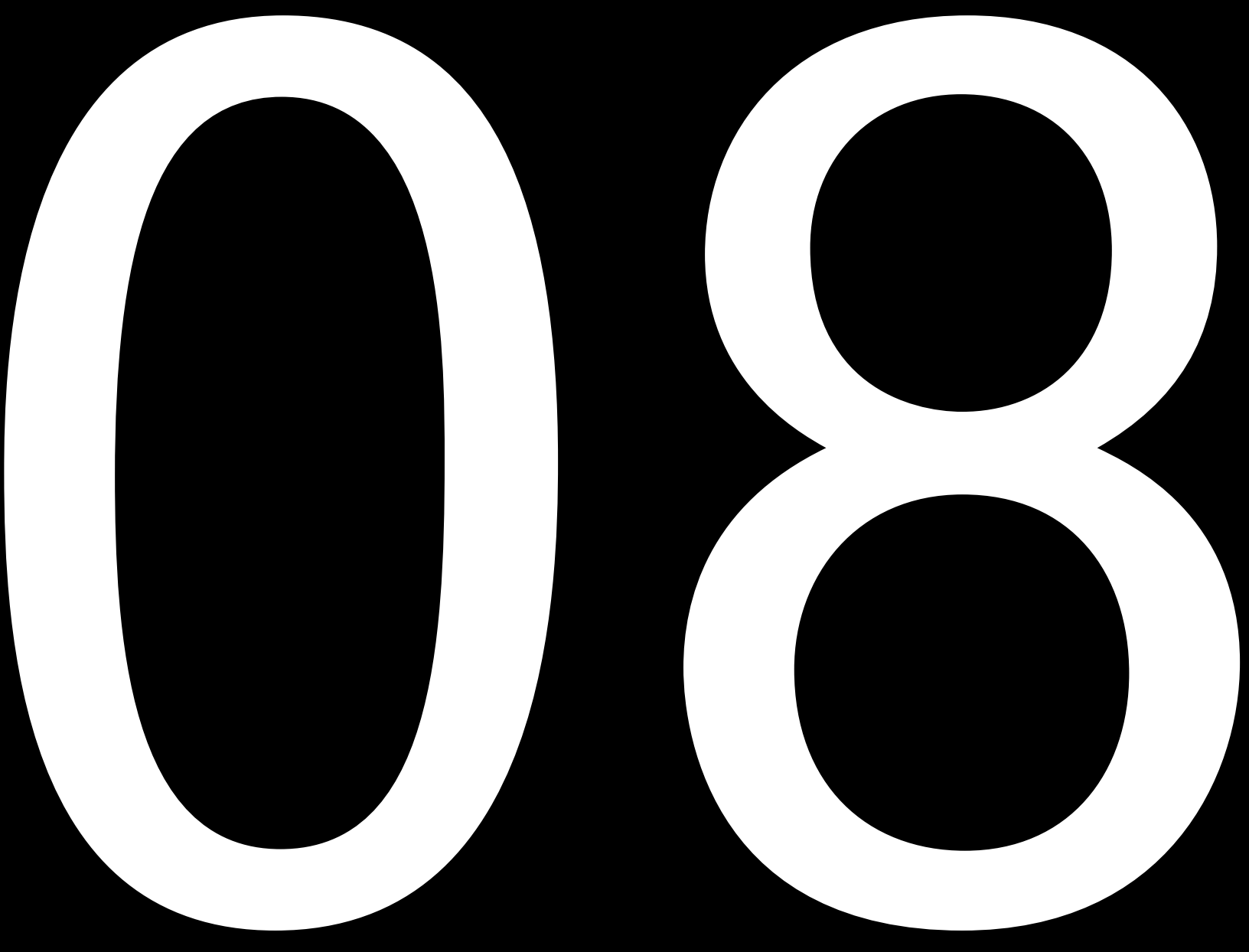

DOI: https://doi.org/10.14483/2422278X.13966 


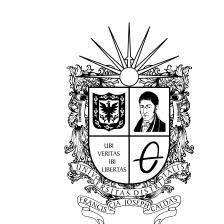

\section{Organizaciones comunitarias de Medellín: red para la construcción de paz a finales de los años 90 y $2015^{1}$}

Community organizations in Medellín: A peacebuilding network at the late 1990s and 2015

Organizações comunitárias de Medellín: rede para a construção da paz no final dos anos 1990 e 2015

\section{Esperanza Milena Torres Madroñero ${ }^{2}$ María Alejandra Botero Botero ${ }^{3}$}

Para citar este artículo: Torres, E. y Botero, M. A. (2019). Organizaciones comunitarias de Medellín: red para la construcción de paz a finales de los años 90 y 2015. Ciudad Paz-ando, 12(2), 99-110. doi: https://doi.org/10.14483/2422278X.13966

Fecha de recepción: 19 de octubre de 2018

Fecha de aprobación: 10 de octubre de 2019

\footnotetext{
1 Este artículo es producto de las reflexiones de la investigación "Repertorios de articulación social y comunitaria para la construcción de paz en la ciudad de Medellín entre 1990-2015”, desarrollado por el Grupo de Estudios en Desarrollo Local y Gestión Territorial de la Facultad de Ciencias Sociales de la Institución Universitaria Colegio Mayor de Antioquia.

2 Socióloga. Magíster en Comunicación. Candidata a doctora en Ciencias Sociales y Humanas. Docente investigadora, Institución Universitaria Colegio Mayor de Antioquia. Grupo de investigación en estudios de desarrollo local y gestión territorial. Correo electrónico: esperanza.torres@colmayor.edu.co, ORCID: https://orcid.org/0000-0002-4711-756X

3 Profesional en Planeación del Desarrollo Social. Investigadora, Grupo de estudios en desarrollo local y gestión territorial, Facultad de ciencias sociales. Institución Universitaria Colegio Mayor de Antioquia. Correo electrónico: botero.male@gmail.com, ORCID: https://orcid.org/0000-0002$7323-4962$
} 


\section{RESUMEN}

Este artículo parte del entendimiento de la red social como una apuesta epistemológica y teórica que invita a la reflexión sobre las subjetividades en relación como potenciadoras de hermanamientos. En concreto, se realiza un acercamiento a la Red de Organizaciones Comunitarias de Medellín, una articulación que emerge en el contexto de la globalización económica e instalación de diversas violencias en el nivel urbano. Esta red se configura como un poder contrahegemónico y una práctica emancipatoria desde la formación de sujetos políticos-críticos que se movilizan y comunican de manera alternativa en el marco de la lucha por la vida digna como principio y consigna de actuación. Dicho abordaje parte de la teoría de las redes sociales, la teoría política y la sistematización de experiencias.

Palabras clave: red social, paz, derechos humanos, vida comunitaria, transformación social..

This article begins with an understanding of social networks as an epistemological and theoretical position that invites reflection on the subjectivity of enhancing twinning. Specifically, the authors introduce Medellín's Network of Community Organizations, which emerges in the context of economic globalization and the onset of various types of violence in urban areas. This network is formed as a counter-hegemonic power and an emancipatory practice on the basis of the formation of politically critical subjects who mobilize and communicate in a different way within the struggle's framework for a decent life as a principle and order of action. This approach is formulated on the basis of social network theories, political theory and the systematization of experiences.

Keywords: social network, peace, human rights, community life, social transformation.
Este artigo baseia-se na compreensão da rede social como uma aposta epistemológica e teórica que convida à reflexão sobre as subjectividades em relação aos potenciadores da geminação. Especificamente, é feita uma aproximação à Rede de Organizações Comunitárias de Medellín, uma articulação que surge no contexto da globalização econômica e da instalação de várias violências em nível urbano. Esta rede se configura como um poder contra-hegemônico e uma prática emancipatória da formação de sujeitos político-críticos que mobilizam e comunicam de forma alternativa no marco da luta por uma vida digna como princípio e slogan de ação. Esta abordagem baseia-se na teoria das redes sociais, na teoria política e na sistematização das experiências.

Palavras-chave: rede social, paz, direitos humanos, vida comunitária, transformação social. 


\section{Introducción}

Las luchas por la construcción de paz en contextos de exclusión y guerra han sido un reto para varias generaciones en el territorio colombiano. Sin embargo, desde múltiples discursos y prácticas, se ha posibilitado no solo la comprensión de las violencias, sino la incorporación de aprendizajes para avanzar en el anhelo de otro mundo posible. En este sentido, la paz tiene un sustrato amplio de significaciones asociadas a la intersubjetividad de los colectivos, sus apuestas y reivindicaciones a lo largo del tiempo, que hacen de estos un lugar de encuentro entre voluntades políticas y fuerzas sociales, y una convergencia entre los procesos de desarme y las resistencias de las comunidades. Es así, que la firma del acuerdo con las Fuerzas Armadas Revolucionarias de Colombia (Farc) y el Gobierno de Juan Manuel Santos implicó no solo la desmovilización de uno de los grupos armados de mayor antigüedad en Latinoamérica, sino que también revitalizó la necesidad de reflexionar alrededor de los sujetos, los vínculos y las apuestas históricas por la paz en el país.

Las iniciativas de construcción de paz se relacionan con las dinámicas de violencia como con la apertura de oportunidades políticas durante diferentes procesos de negociación, de ahí las transformaciones de la movilización y la diversidad de sujetos participantes. En el caso concreto de Medellín, desde los años 60 y 70 se referencian procesos sociales y comunitarios en busca de alternativas que prevalecieran por encima del conflicto a partir de la lucha por un lugar donde vivir. Posteriormente, para la década de los 80 en el marco de procesos sociales y políticos complejos emergen discursos y apuestas de reivindicación de necesidades de infraestructura y servicios sociales en un deseo de integración a la ciudad. En los 90, emergen experiencias de planeación del desarrollo pensadas en articulación entre diversos actores y a escalas de acción más amplias que la de barrios y comunas para la consecución de mejores condiciones de vida. Finalmente, en los años 2000 sobresalen nuevos actores, como jóvenes, mujeres y víctimas, con repertorios simbólicos que generan importantes escenarios de reflexión-acción para la promoción y protección de los derechos humanos, la convivencia, la justicia y la transformación de significados y discursos tradicionalmente aceptados en la cultura hegemónica-patriarcal.

Así, el presente artículo tiene como objetivo reconocer la Red de Organizaciones Comunitarias de Medellín (ROC) como una acción colectiva constructora de paz en el contexto de violencia a partir de su movilización y lucha por la vida digna. Para ello, en el texto se intenta establecer un diálogo entre las categorías: redes sociales, construcción de paz, y repertorios de acción, bajo el prisma analítico de la teoría política crítica con la noción de poder contrahegemónico. En particular, la primera perspectiva fue un elemento nuclear del estudio por posibilitar una apuesta epistemológica y teórica que reconoce un sujeto relacional, flexible, dinámico y en redefinición. A su vez, la perspectiva invita a un ejercicio hermenéutico, en términos de Gadamer (2010), donde la imbricación de los actores entre sí y el investigador en el proceso de conocer, gesta una realidad entretejida y diversa. En el caso concreto de Medellín, las redes sociales son leídas como actores que se vinculan en los territorios excluidos del desarrollo y del proyecto moderno para confabular acciones en pro de la justicia, la memoria y la vida digna, es decir, para generar un tejido de voluntades y acciones interconectadas que tienen lugar en un espacio-tiempo determinado con intermitencias y momentos de redefinición y transformación.

La crisis de la lógica moderna, y con ella las formas de participación tradicional ceñidas a la vinculación partidista y mecanismos formales que trajo consigo la figura del Estado, requirió de nuevos actores y maneras de accionar desde la vida cotidiana. Estos modos de organización abrieron camino a estrategias políticas colectivas en escenarios locales y nacionales donde se empezaron a vislumbrar otras racionalidades no instrumentales, emancipadas y con apuestas de construcción de futuros plurales y solidarios. Asimismo, la actuación en red dejó de lado la lectura fragmentaria de los territorios y comenzó a constituir otros lugares para la actuación política y para los aspectos no resueltos por la modernidad.

En este orden de ideas, la red como concepto y forma de actuación tiene lugar en la ambivalencia de su sentido y en la lectura instalada desde la globalización económica. Por un lado, la red se presenta como respuesta a las demandas del contexto producto de la desregulación de las instituciones modernas, específicamente, como una estrategia para la competencia; por otro lado, se deja ver como un modo contrahegemónico de consolidar otras formas de poder desde la cuadra y el barrio, como escenarios, y la exigencia por los servicios públicos y la defensa de la vida digna, como emblemas en el contexto para las luchas sociales. En otras palabras, se trata de lo que autores como Bauman (2014) definen como "la colectivización de los problemas junto con la privatización de los instrumentos y de los medios para resolverlos" ( $p$. 147), que a su vez ha posibilitado la diversificación y ampliación de los escenarios para el ejercicio político y la formación de racionalidades comprensivas y para la vida.

De este modo, la globalización transformó las formas de relacionamiento pensadas por algunos para la vinculación competitiva en el mercado, y para otros, como estrategias de resistencia creadas desde el hermanamiento y la confianza para gestar acciones colectivas que van en contravía al sistema valorativo, que lleva consigo el capitalismo como sistema económico, político y cultural. En el marco de esta última orientación, el estudio se centró en el entendimiento de las redes sociales como hermanamientos, enjambres, nichos de personas que se entrelazan para la búsqueda de objetivos comunes y que 
trascienden el individualismo y la competencia, en tanto se gestan en la solidaridad y en el trabajo mancomunado, así como en la formación conjunta de capacidades para resistir y sobrepasar diferentes formas de violencias en los territorios.

Estos relacionamientos se despliegan en un contexto que inhibe, pero que a su vez crea las condiciones que particularizan el accionar colectivo y los sujetos que se encuentran en esa acción (González, 2006). Por lo que la violencia no se entiende como un suceso, sino como una serie de factores que se instituyen en el contexto, denominado por González (2006) como el contexto de violencia, donde tienen cabida factores como la desigualdad y la exclusión. La paz no es entonces entendida como ausencia de actos de violencia, sino como aquellos procesos que se llevan a cabo en los territorios para revertir los efectos negativos del contexto, visto así, esta adquiere una connotación como discurso movilizador, práctica colectiva y búsqueda política, que convoca una diversidad de actores públicos, privados, académicos y sociales-comunitarios y no solamente hace referencia a la faceta antagónica de la guerra o las confrontaciones armadas.

Este tipo de relacionamientos es particularmente ejemplificado por la ROC de Medellín, pues desde diferentes lugares vehicula su accionar hacia la defensa de la vida digna, la superación de la pobreza, la discusión sobre los efectos del neoliberalismo y el capitalismo, los derechos humanos y la memoria. Dicha red configura agendas que movilizan y recrean identidades colectivas alrededor de resistencias compartidas en una diversidad de actores, al mismo tiempo que se convierte en escenarios de confluencia de organizaciones y procesos de la ciudad. Ello conlleva a la ampliación del campo político y da lugar a resistencias y alternativas contrahegemónicas (De Soussa, 2010). La ROC es, por tanto, una red de voluntades, actores y búsquedas, que permiten dar cuenta de cómo la paz se ha dinamizado en los territorios a lo largo de la historia y cómo las subjetividades se entrelazan históricamente desde la confianza, para posibilitar transformaciones y luchas en los territorios que vivencian la exclusión.

En esta medida, el presente ejercicio se nutre de las discusiones propiciadas desde las perspectivas críticas de las ciencias sociales con la investigación participativa, la educación popular, y en concreto, con la metodología de sistematización de experiencias, entendida como un proceso de aprendizaje y socialización, pero también como forma de producción de saberes. En este sentido, se entiende el acto de conocer como una acción política, desde donde se genera el cuestionamiento a los lugares de enunciación que construyen relatos sobre la experiencia. Lo anterior deja ver como metodológicamente el texto que se presenta es resultado de un diálogo entre algunos actores representativos de la ROC y el grupo de investigación, lo que posibilitó reflexionar la experiencia con insumos como la entrevista a profundidad y el taller de línea de tiempo. Este proceso de construcción de información se dinamizó en torno a tres ejes: el contexto, los sujetos y las agendas, con ayuda de una revisión documental y matrices de análisis que permitieron trazar la ruta de este relato bajo el prisma de la construcción de paz.

Asimismo, en la construcción del método se establecieron dos premisas mínimas: en primer lugar, la escritura de la experiencia debe ser un acto ético que devele las relaciones de poder de las que es parte; en segundo lugar, las investigadoras, como actores dentro del proceso, construyen una voz propia en el aprendizaje que se posibilita en la relación dialógica donde interpelan referentes, reflexiones y subjetividades propias, por lo tanto la presente construcción no reemplaza ni intenta ejercer una acción performativa de la voz de quienes tutelan la experiencia ya que este producto emerge gracias al diálogo y vuelve a él como parte de un proceso hermenéutico en el cual se resguarda la circularidad, horizontalidad y la no jerarquización en la construcción de conocimiento.

En consideración a los aspectos enunciados, el artículo se estructura en tres partes. Inicialmente, se aborda la red social como apuesta epistemológica y teórica del ejercicio. En un segundo momento, se describe el contexto de emergencia de la ROC. Finalmente, se da cuenta de la ROC y sus repertorios de acción, para finalmente presentar algunas reflexiones y aprendizajes desde esta red para la construcción de paz en el país.

\section{Las redes sociales: apuesta epistemológica y teórica}

La red social es un concepto polisémico, interdisciplinar y viajero, en términos de $\mathrm{Bal}$ (2002), la aproximación a su definición da cuenta de su amplia posibilidad de significaciones y de los abordajes que ha tenido desde diversos campos disciplinares: la antropología, las comunicaciones, los estudios organizacionales, la sociología, el trabajo social, los estudios e intervenciones en salud, etc. Ello ha gestado un amplio bagaje de comprensiones que se reelaboran en dependencia de los contextos desde donde se piensa, de los intereses investigativos, de la mirada y la distancia de los campos de conocimiento (Simmel, 2014), y en especial de la interactividad entre el sujeto y el objeto de conocimiento (Bal, 2002).

El acercamiento a las redes sociales se inscribe en el cuestionamiento al modo de relacionamiento humano. El contexto neoliberal no solo conllevó una transformación en la lógica de la economía y el reordenamiento del poder global, sino que también permeó las posibilidades de interacción humana, su sentido y sus formas. Se bifurcan las maneras de relacionamiento, las interacciones pensadas en función de la racionalidad y la forma cómo conviven con vínculos difusos, móviles, reticulares y sin estructuras 
fijas. Por lo tanto, la red social es uno de los observables de un cambio de paradigma que transgrede el modo mecánico de concebir el universo a uno que se cimienta en el dinamismo y la fluidez y que demanda para sí una apuesta teórica, metodológica y ontológica desde la complejidad.

En este sentido, en su conceptualización se pueden identificar afluentes diversos, inicios múltiples que se entrecruzan. Al respecto Luna (2014) sostiene que las redes sociales han gestado una amplia riqueza y diversidad de aproximaciones para las Ciencias Sociales que pueden sintetizarse en tres enfoques: en primer lugar, la perspectiva denominada análisis de redes sociales, en segundo lugar, la teoría del actor-red y el enfoque de la red como mecanismo de coordinación social. La autora afirma que estos acercamientos tienen como elemento común la preocupación por analizar diferentes dimensiones tales como: la disposición de los actores, las razones por las cuales se originan, las trayectorias, las estrategias, las razones de desaparición, entre otras.

Según Luna (2014), desde la primera perspectiva, la red se entiende como un sistema de vínculos entre nodos o entidades sociales. Como instrumento, busca medir grados de centralidad y densidad, al igual que clasificar, en función de la distancia social y de los actores que la configuran, su composición como redes hemofilias o heterofilias. De suerte que desde esta mirada, la preocupación está centrada en dar cuenta de la morfología, formalización y representación gráfica de los vínculos. El análisis de redes se considera como la perspectiva de mayor auge y reconocimiento debido a que ha tenido aplicaciones en diferentes campos del conocimiento, la política y la economía, aunque tiene un estatuto menor dentro de las teorías y se acerca más a un instrumento analítico con relevancia en los años 90.

El actor-red, por su parte, tiene un estatuto mayor dentro de las teorías sociales. Como tal emerge en los años 80 y detalla aspectos como la diferenciación, la autonomía de la red y los actores que la constituyen, por lo que esta perspectiva cuestiona las separaciones originadas por la lógica de la modernidad, entre ellas, la establecida entre la naturaleza y la sociedad (Luna, 2014). En otras palabras, este acercamiento intenta dar cuenta de la complejidad de los vínculos sociales que comprende a humanos y no-humanos que se enlazan para alcanzar metas específicas, por lo que se trata entonces de analizar las alianzas entre personas y cosas que conectan a la gente (Luna, 2014) y de dar cuenta de la dinámica de las redes lograda gracias a lo que dentro de dicha teoría se conoce como la "traducción", la cual posibilita el vínculo, el intercambio y la puesta en común de aspectos que convocan y mueven la red social, ya que son las "negociaciones, intrigas, cálculos, actos de persuasión y violencia, por los cuales un actor o una fuerza adquiere autoridad para hablar o actuar en representación de otro actor o fuerza" (Luna, 2014, p. 65).
Desde esta mirada, las redes sociales evolucionan y es posible identificar en ellas tres fases. La emergencia de la red, donde la traducción es importante en la medida que permite construir el inicial lenguaje común. El desarrollo de la red, donde se construye la lógica y la traducción que puede forjar lugares de encuentro y de desencuentro. Finalmente, la estabilización de la red, que tiene lugar cuando esta se ha diferenciado mucho más y genera mayores niveles de complejidad y estabilidad (Luna, 2014). Esta lectura de la red permite entenderla como un complejo sistema de traducciones para posibilitar el vínculo, dinamizarlo y posicionarlo.

En cuanto a la comprensión de la red como modo de coordinación, el concepto es entendido como sistema complejo donde la diferenciación, especialización e interdependencia entre diversos sistemas (el social, el político, el económico, el científico y el educativo) se interconectan para la solución de problemas más allá de las organizaciones, los sectores o los individuos. Bajo esta perspectiva, las redes se entienden como entidades que buscan su autorregulación a través de la interdependencia y la comunicación entre sus elementos, donde se dan relaciones de tensión, de cooperación y de conflicto (Luna, 2014).

Para el abordaje del presente estudio, la red se asume como una construcción polisémica que lleva implícita una postura epistemológica, pues se trata de sujetos relacionales en el proceso de investigación que particularizan el método de trabajo y el tipo de conocimiento que se desprende del ejercicio. Desde este punto de partida, la ROC no es un elemento estático, definido o delimitado, ya que este se teje desde la complejidad, la flexibilidad y su constante transformación. Ello plantea una relación hermenéutica entre el investigador y lo investigado, una vinculación desde la horizontalidad y desde la mutua influencia entre sujetos de conocimiento que permite entender la teoría como un recurso inacabado, provisional y resultado de la relación del investigador con aquello que investiga (Gadamer, 2012 y Bal, 2002). En esa dirección, pensar en las redes sociales dialoga con el pensamiento complejo e invita a la reflexión de un sujeto de investigación relacional inscrito en unas condiciones socio históricas que produce y se produce en el proceso investigativo.

Como lo expresa Najmanovich (2001), el mito objetivista de la modernidad es puesto en cuestión con nociones como las de la red, y con ello adquiere relevancia el "mito del sujeto" con el giro consecuente a las preguntas por los vínculos y la interacción, entendidos "como formas básicas de la experiencia humana” (p. 106). Ese despliegue hacia la subjetividad y la experiencia reclama a su vez, otras lecturas multidimensionales, no lineales, que permitan "dar cuenta de las paradojas constitutivas de nuestro modo de experimentar (nos)" (p. 106). En consecuencia, el acercamiento al problema de investigación desde la noción de la red invita a la incorporación de un 
concepto y una mirada que transversaliza el ejercicio investigativo en el que requerimos:

Acceder a un espacio cognitivo caracterizado por las formaciones de bucles donde, por un lado, el Sujeto construye al Objeto en su interacción con él, y por otro, el propio Sujeto es construido en la interacción con el medioambiente natural y social. No nacemos "sujetos" sino que devenimos tales y a través del juego social. (Najmanovich, 2001, p. 106)

La lectura desde la complejidad y desde la crítica al modelo de la modernidad, permite abordar la red como una apuesta metodológica en sí misma, y a su vez como un objeto y sujeto de investigación que se redefinen mutuamente. En esta línea, Najmanovich (2001) propone una lectura interactiva que posibilita entender en la red social elementos que trastocan formas de pensar, sentir y actuar, y que se acercan a los vínculos, a los sistemas abiertos, a las organizaciones complejas, no lineales y emergentes. Estos componentes relacionales que pueden observarse en la red interrumpen la lectura dicotómica afianzada desde el pensamiento moderno centrado en el entendimiento de objetos que requieren una definición absoluta que delimite lo que estos son o no son, y donde "la vaguedad, la heterogeneidad son inconcebibles" (Najmanovich, 2001). La red social con la que se entabló un diálogo no puede abordarse desde una lente que privilegie la pureza (el ser es), tal y como lo expresa la misma autora, "la versión monista del mundo no permite entender la interacción transformadora, la hibridación, la interpenetración, el vínculo instituyente y constituyente" (Najmanovich, 2001 p. 106).

Estas características de las redes sociales invitan a comprenderlas como un sujeto relacional, polifacético y dinámico de investigación inscrito en formas de participación política no formal (Reguillo, 2000). Por tratarse de acciones emergentes que tienen lugar en la apertura a un contexto globalizado y de incertidumbre con la crisis de la modernidad, irrumpen las formas de participación moderna y los repertorios tradicionales de acción colectiva, posicionan vínculos de sentido donde se gestan una multiplicidad de afiliaciones y formas de accionar que requieren una permanente reinvención, lo que quiere decir, una constante configuración de otra mirada para conocer y comprender el ejercicio colectivo y vital donde tienen lugar los poderes contrahegemónicos.

\section{Contexto de violencia y oportunidad de la ROC de Medellín}

El contexto de violencia, como categoría de análisis, permite pensar en la historicidad y multidimensionalidad de las violencias, y a su vez en la interrelación estrecha de los repertorios de acción colectiva, las formas organizativas y los sujetos políticos, con las particularidades de los contextos donde emergen. En otras palabras, el contexto de violencia impregna caracteres particulares a las subjetividades, modos de relación, organización y acción social. Al respecto, González (2006) propone leer la violencia en términos de contexto de violencia prolongada, lo cual acentúa la necesidad de captarla desde su complejidad, vinculada a estructuras políticas y sociales, órdenes económicos y simbólicos, que no recaen exclusivamente en los actores armados, sino en otras formas de violencias que se vuelven sistemáticas e históricas. La violencia así entendida es contexto y no exclusivamente una manifestación.

En consideración a este punto de partida, pensar el periodo de finales de los años 90 hasta el 2015 convoca a estimar aspectos de trascendencia en el panorama internacional como las políticas neoliberales de Ronald Reagan, la crisis del Estado de Bienestar, la globalización, y el auge y declive del discurso de la seguridad humana. En el ámbito nacional surge la nueva carta constitucional de 1991 con la subsecuente instalación en el país de un marco normativo que buscaba garantizar la participación política, pero que a su vez daba cabida a las políticas neoliberales iniciadas desde periodos anteriores, por ejemplo, en los años setenta vinculadas a las dictaduras militares en Latinoamérica y en los ochenta, a políticas de ajuste fiscal dirigidas por el Fondo Monetario Internacional, respondiendo a las crisis del socialismo en el mundo cuyo resultante es el sistema capitalista como modelo único de la economía.

La Constitución de 1991 materializa el proyecto de la modernidad en la democracia con centralidad en actores como los partidos políticos, entendidos como organizaciones para el acceso al gobierno y al poder (Gechem, 2009). Estas formas organizativas tienen, desde el Siglo XIX, una vinculación directa con las élites regionales que reproducen en el terreno de lo político las disputas por el poder económico e instalan en los imaginarios sociales la fragmentación bipartidista, liberal y conservador, caldo de cultivo de una conflictividad estructural en Colombia. Los partidos políticos caracterizados por su no horizontalidad, su instrumentalidad a los intereses de las élites económicas y su desconexión como representantes legítimos de las necesidades fraguadas en la vida económica y cultural del país (Fernández y Parra, 2000 ), son uno de los puntos de quiebre del proyecto moderno que se instala empleando el molde de otras latitudes, sin considerar las particularidades históricas de la región, pero que además se sustenta en la conflictividad, la fragmentación territorial y la imposibilidad de construir un proyecto de nación articulado de manera efectiva.

En otras palabras, y como lo expresa Fernández y Parra (2000), la conformación del sistema político colombiano involucró un proceso de adaptación de la concepción moderna que se concreta con el Estado Nacional 
Representativo. Dicho sistema político implica el marco normativo, que en el caso colombiano queda estipulado con la Constitución de 1991, pero a su vez la dimensión sociocultural que atraviesa la subjetividad política del país donde queda manifestada su historicidad, el marco de valores, las formas de relación social, entre otras.

Como lo expresa Kalmanovitz (2001), la Constitución Política de Colombia se puede entender "como un compromiso entre fuerzas con inclinaciones social-demócratas, otras liberales y conservadoras" (p. 9). Desde su configuración, el sistema político colombiano padece de una doble fractura interna, por un lado, como afirma Restrepo (1992), la Carta Magna encarna el discurso del bienestar social y el de la competencia, lo cual conlleva a prácticas en contradicción; por otro lado, la fractura entre las condiciones reales de vida que impregnan la dimensión social y las promesas de justicia e igualdad desplegadas en la norma. En igual sentido, el sistema político evidenciaba una serie de obstáculos, tal y como Fernández y Parra (2000) manifiestan:

por una parte, una clase política sólida y retardataria; y por otra, unos partidos políticos tradicionales, con estructuras débiles, carentes de un ideario que cohesionara las voluntades en torno a los intereses generales y de una disciplina que les permitiera accionar organizadamente, al igual que contar con una dirección que, movida por sus apetencias exclusivamente electorales, había permitido y propiciado su fraccionamiento. (p. 4)

De manera paradójica, la institucionalización de la participación en Colombia se forja simultáneamente con la oleada de violencia en las ciudades. Para Medellín los años noventa representaron el punto más alto en la tasa de homicidios, una realidad que asciende hasta el $42 \%$ sobre el total de fallecimientos en la ciudad en el año de 1991 (Cardona et al., 2005). La agudización de la conflictividad urbana era la manifestación abierta de los poderes que se tejían en el territorio, entre la Medellín planificada y la creada desde la carencia y la exclusión sistemática, y que dio lugar a otros órdenes diferentes al legal como reguladores de diversos escenarios de la urbe.

En ese panorama, el contexto de violencia y oportunidad en los años noventa vincula las contradicciones de la racionalidad moderna incompleta por diversos motivos, dentro de los cuales están: una dinámica entre procesos de apertura democrática relacionados al nuevo marco normativo; la exacerbación del modelo económico capitalista acentuado en políticas neoliberales con las premisas de la libre competencia y el libre cambio como sus principales consignas; y la conflictividad emergente de procesos de planificación fracturados en la ciudad, que posibilitaron la existencia de órdenes legales e ilegales.

$\mathrm{Al}$ marco normativo favorable para nuevas formas de participación y organización social, se suma el despliegue de actores sociales y comunitarios que en sus búsquedas de una ciudad-país más humana dinamizan acciones colectivas por la vía de movilización de opinión, concertación y gestión de recursos, y se posicionan en el debate público. El discurso de los derechos humanos y la movilización en busca de su garantía, entre otros, delimitan un contexto de oportunidad para dar lugar a otros repertorios de acción que rompan las formas tradicionales de organización política anclada a los partidos políticos y que se expresen de maneras más flexibles, dinámicas y horizontales, como es el caso de las redes sociales y comunitarias en Medellín.

En definitiva, la emergencia y expansión de redes sociales y comunitarias fue producto de la confluencia de factores como la crisis de las formas de participación tradicional vinculadas al sistema de partidos políticos en el país y al panorama de globalización y neoliberalización dado en los años noventa, el cual favorece la presencia de otros actores como las organizaciones no gubernamentales. Ante la fragmentación de la cuestión social se requirió la intervención de actores privados para la atención de las demandas sociales (Carballeda, 2002), lo que implicó la intervención de agentes externos en el país, así como procesos de "formalización" de organizaciones en la ciudad que demandaron repensar los repertorios de acción en un contexto de tensión entre las convicciones de la acción colectiva, sus trayectorias y los retos del panorama neoliberal.

En este orden de ideas, el movimiento comunitario se enfrentó a la disyuntiva entre la supervivencia y la emancipación; a la búsqueda en la construcción de confianzas y capacidades; a la interlocución y cooperación técnico-financiera de organizaciones públicas y privadas; $\mathrm{y}$ a varias estrategias encaminadas al posicionamiento comunitario en la escena pública. Así, desde iniciativas como los procesos de planeación zonal y la conformación de articulaciones, mesas y comités se empiezan a tejer relaciones entre actores diversos, en ocasiones contradictorios, para pensar y construir desde las diferencias apuestas por una vida digna.

\section{La ROC de Medellín: poder contrahegemónico en la lucha por una vida digna desde repertorios de acción solidarios y vitales}

La ROC es el resultado de los cambios en las formas organizativas y en los tránsitos de personas, organizaciones comunitarias y procesos de ciudad. Emerge como idea desde el año 1997 cuando se piensa como un proyecto de confianzas y nuevas confluencias que en el diálogo ponen de manifiesto la necesidad de consolidar una articulación con mayor posibilidad de alcance e influencia de acciones en las comunidades, como en la toma de decisiones. De modo que se consolida como proyecto entre el periodo 1999-2000 con el apoyo de la Agencia Española de 
Cooperación Internacional (AECI; ROC, 2004; Memorias Taller Línea de Tiempo ROC, 2017).

Fue una propuesta de intercambio para el fortalecimiento, reconocimiento y generación de un movimiento social con incidencia y participación de la voz comunitaria en la construcción de una agenda política para el desarrollo de mejores condiciones en los sectores rurales y urbano-populares, históricamente marginados, de Medellín. Como articulación, logró la vinculación de organizaciones, acciones políticas, voluntades individuales y colectivas encaminadas a satisfacer necesidades a partir del establecimiento de vínculos, valores, estrategias y acciones entre diversos sujetos que desde la diferencia de saberes, formas de aproximarse y significar la realidad se entrelazaron en intereses, intenciones, intentos, emociones e historias.

Hoy, pensar en esta red invita a comprenderla desde su devenir en el tiempo, sus potencialidades y tensiones como un tejido dinámico y polifacético con múltiples posibilidades de focalización, al igual que representaciones, de ahí, como se indicó al inicio del texto, emana su difícil aprehensión. En una mirada histórica del hacerse y deshacerse de la ROC, es posible identificar distintas trayectorias, sujetos, maneras de organizar la acción y significarla, que evidencian las subjetividades, así como las coyunturas del contexto en el que se desenvuelve. Igualmente, la complejidad y diversidad en sus modos de relacionamiento es posible observarla en la convivencia simultánea de individualidades y colectividades, en la interacción local-global, los modos de proceder desde lo festivo-orgánico y el debate entre lo institucional-comunitario.

En este sentido, es probable leerla de dos maneras distintas y opuestas que se entrecruzan. Por un lado, como estrategia para la supervivencia a partir de la exigibilidad de derechos y gestión de recursos; y por otro, como estrategia de emancipación a través de autogestión, movilización y construcción de un sujeto político. Sin embargo, la lucha por la vida digna y la configuración de un poder contrahegemónico son un componente común y vital del sentido de la misma. Esta apuesta, constituye una alternativa de poder crítico porque cuestiona las grandes enunciaciones, el modelo de desarrollo económico, las prácticas políticas tradicionales y las lógicas militaristas, además propone caminos para la transformación de la realidad desde las propias vivencias y necesidades de las minorías, con un enfoque centrado en justicia, equidad, solidaridad y democracia.

Pese a las grandes dificultades en la conformación y consolidación de la red, como se observa en su accionar histórico contra la desesperanza, fue una experiencia solidaria que permitió un mayor eco a la visibilización de las condiciones de exclusión, un intento de confluencia de búsquedas y "una posibilidad para la movilización social consistente, estructurada y formativa" (Entrevista
Villa, 2018). Significó un espacio de articulación desde la intersección de experiencias comunitarias y organizativas que, ante las demandas del contexto, hicieron de la lucha por la dignidad de los territorios un emblema para la movilización colectiva en un intento por evidenciar la demanda ante el orden gubernamental por el acceso a satisfactores vitales para la subsistencia, fortalecer procesos de autogestión que reivindicaran la calidad de sujetos sociales y políticos, de los habitantes en los territorios, así como la posibilidad de gestar dinámicas de formación, en términos políticos, fundamentados en el diálogo y la crítica a las violencias instituidas en el contexto.

En lo que sigue, se aborda la red desde los sujetos en-redados y su funcionamiento a partir de hitos históricos en un intento de profundizar en la naturaleza solidaria y en su potencialidad crítico-emancipadora, sin perder de vista aquellos matices que construyen su particularidad.

\section{Individualidades y colectividades: los sujetos enredados}

Como ya se planteó, en esta investigación las redes sociales son entendidas como hermanamientos por tratarse de nodos de personas en un proceso permanente de interacción e intercambio de trayectorias, opciones y discursos para la búsqueda de objetivos comunes. Son los sujetos quienes, desde su participación en contextos organizacionales y espaciales, configuran los sentidos de estar en red, los modos de relacionamiento y apuestas que, a su vez, multiplican posibilidades u obstaculizan acciones. Por tanto, se convierten en una dimensión central en el propósito de desenredar la ROC. No obstante, la coexistencia de unidad-heterogeneidad que la compone, conlleva a la dificultad para precisar quiénes son los actores que convocan y mueven la red, así como los múltiples tejidos que se refuerzan o se deshacen en su permanente autoorganización, puesto que integra colectivos de individuos con valores y principios particulares que de manera simultánea gestan varios vínculos y afiliaciones a territorios y organizaciones.

La ROC convocó diversidad de actores públicos, privados, sociales-comunitarios y académicos que se observan en diferentes nodos según vínculos y actuación (Figura 1). Estos cambian con el tiempo y coyunturas: unos aparecen en situaciones concretas, otros se sustraen, mientras algunos permanecen, pese a ello, todos son agentes determinantes en su historia. En un primer nodo, aparecen las organizaciones que integran propiamente la red. En un segundo punto del diagrama, aparecen algunas ONG que acompañan o aportan técnica o económicamente a las organizaciones barriales, en especial a las "pequeñas", en un ejercicio de "apadrinamiento". Desde otro punto de vista, se visualizan instituciones públicas y privadas que apoyaron la gestión y sostenibilidad de la red, tales como las agencias de cooperación internacional, entidades del 
Estado y universidades. Finalmente, otra "partícula" existente son las redes o articulaciones de nivel local, regional y nacional a las que se une la ROC para actuar desde otros lugares.

En una mirada de focalización hacia los sujetos que intervienen directamente en la red se encuentran hombres y mujeres defensores de derechos humanos, jóvenes críticos ante el sistema económico y las dinámicas guerreristas, líderes comunitarios, activistas sociales o militantes, que con visos de voluntad y esperanza deciden participar como actores políticos en representación de procesos de ciudad y organizaciones comunitarias de primer y segundo grado. Son individuos y colectivos que a partir del interrogante " ¿cómo generar unidad en la diversidad?" (Entrevista personal, Franco, 2018) ponen de manifiesto la existencia de múltiples formas para desaprender las violencias y aprender a hacer las paces, además, de la importancia de reconocernos unos a otros y juntar iniciativas para avanzar en el anhelo.

Las organizaciones de base de la ROC se diferencian por sus lugares de actuación, escalas de acción y énfasis en estrategias, tanto como en las poblaciones. Algunos referentes reveladores de las prioridades en las propuestas que cada base define son la planeación participativa y gestión del desarrollo local, la promoción de bienestar y desarrollo humano integral, la identidad-reconstrucción del tejido social, la integración comunitaria, la convivencia y promoción, y la gestión sociocultural. Otras, por su parte, ponen el enfoque en poblaciones específicas que son vulneradas en un contexto con lógicas patriarcales, como es el caso de niños, niñas, jóvenes y mujeres. También se visibilizan las particularidades en los tiempos de permanencia, la capacidad de gestión y los relacionamientos con otras organizaciones pares e instituciones públicas y privadas. En este último punto, se destacan disimilitudes respecto a mayores cercanías con el Estado y distanciamiento, así como la inclinación hacia la gestión de recursos versus autogestión (ROC, 2004; Memorias Taller Línea de Tiempo ROC, 2017).

Sin embargo, estos actores encontraron en su disparidad la oportunidad para potenciar puntos en común, como el trabajo por la vida digna de las comunidades y sectores vulnerados, horizontalidad, autonomía en la toma de decisiones, resistencia frente a discursos tradicionales para tener en cuenta posiciones ambientalistas, de buen vivir, de género, interculturalidad, no violencia y derecho a la ciudad. De igual manera, se presenta la manifestación de un sistema de valores frente a la empresa privada y las burocracias del Estado en el que la solidaridad, la democracia, la equidad, la justicia social y la convivencia son la base (ROC, 2004; Hidalgo y Restrepo, 2001).

En cuanto a las afinidades entre las organizaciones es preciso destacar la formación como eje transversal en las áreas y metodologías de trabajo concebida desde los postulados de la educación popular, en la cual "la práctica de la libertad solo encontrara adecuada expresión en una

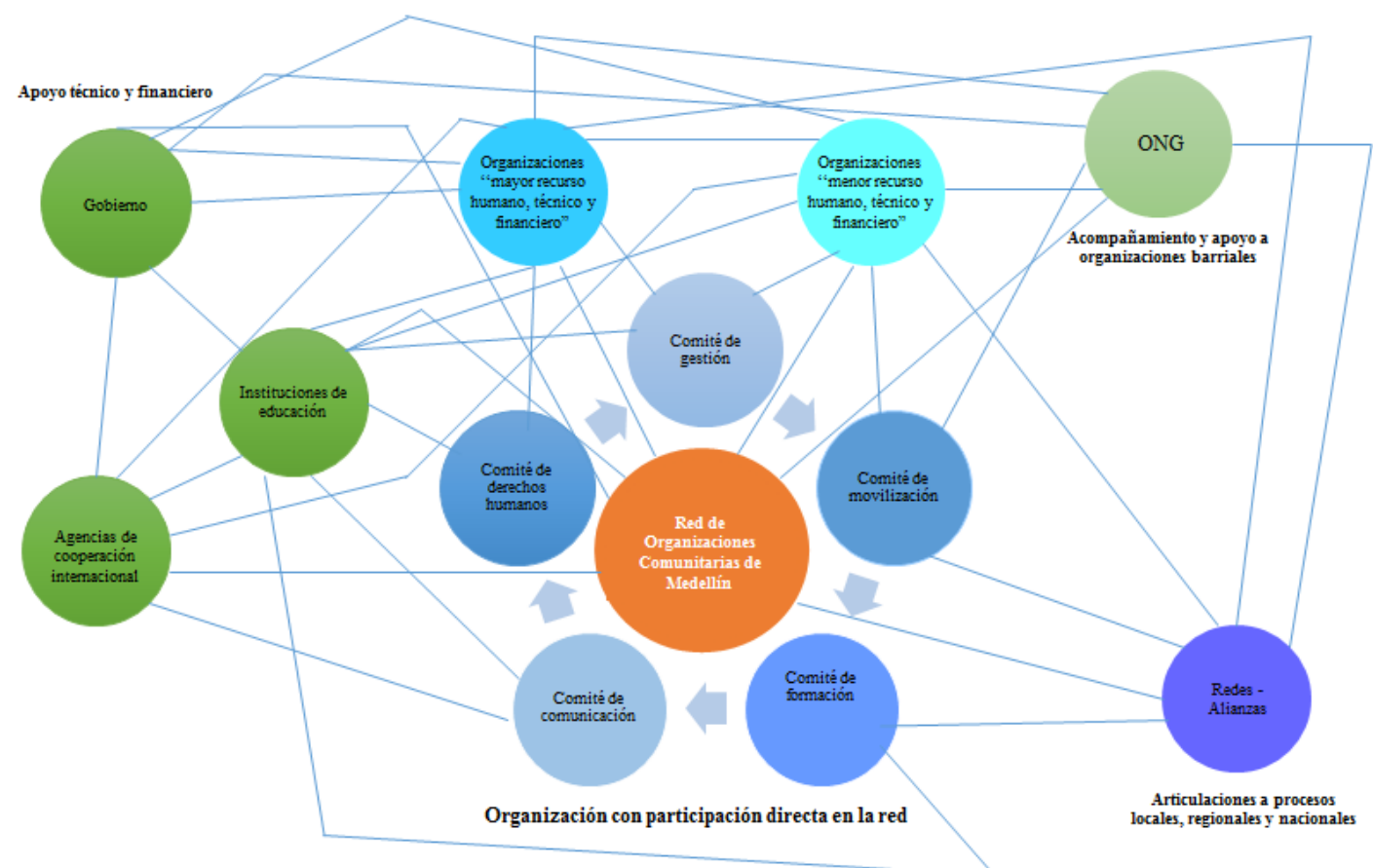

Figura 1. Organizaciones ROC de Medellín Fuente: elaboración propia. 
pedagogía en que el Oprimido tenga condiciones de descubrirse y conquistarse, reflexivamente, como sujeto de su propio destino histórico" (Freire, 2005, p. 6). De modo que se apuesta por un modelo crítico y participativo en el que se construye conocimiento colectivamente y se contribuye a la configuración de sujetos rebeldes, solidarios, activos y comprometidos con las transformaciones del entorno que habitan.

\section{Relacionamientos en movimiento: los ciclos de la ROC}

En el ejercicio de análisis se construyeron hitos asociados según énfasis en los conjuntos de acción y sus sentidos, en concreto se detallan cuatro fases. En un primer momento, la construcción de un lenguaje común y búsqueda de identidad comunitaria: pensarse juntos el proyecto de la red (1999-2001). En segundo momento, la puesta en marcha: la red se moviliza por la vida, protección y construcción de capacidades de las organizaciones comunitarias (2002-2003). Para un tercer momento, los lazos se afianzan y el reto se intensifica: la red en acción por la exigibilidad de los servicios públicos como un derecho fundamental (2004-2009). Por último, nuevos ciclos de vida: la red aviva y potencia diversos procesos de ciudad (2010-2015).

- La construcción de un lenguaje común y búsqueda de identidad comunitaria: pensarse juntos el proyecto de la red (1999-2001)

Esta fase acontece en un contexto complejo de agudización del conflicto y en un escenario político poco favorecedor que limitaba los espacios de participación y visualización del tercer sector y sus iniciativas. En consecuencia, aparecen ideas de poder volver la mirada a los territorios, aspiraciones por alzar las voces de los marginados e interrogantes frente a cómo desde los sectores comunitarios se llegaba a escenarios de poder local, la preocupación por establecer diálogos en torno a la conceptualización y significación de la organización comunitaria y el reconocimiento de aprendizajes pasados (Memorias Taller Línea de Tiempo ROC, 2017).

Se parte de ejercicios de sistematización de experiencias de redes de organizaciones comunitarias en la gestión del desarrollo de los años 80 y 90 como línea de proyección y encuentros previos de integración e identificación del estado de las organizaciones, así como de las propuestas y expectativas en torno a la construcción de paz. La dinámica, entonces, se centra en generar espacios de debate para identificar las capacidades, reconocerse, tejer confianzas y pensarse como red hacia la visibilización y fortalecimiento de lo comunitario como una alternativa a las múltiples violencias instauradas en la ciudad. Además, se reivindica el saber popular y la memoria como forma de lucha.

\section{- La red se moviliza por la vida, protección y construcción de capacidades de las organi- zaciones comunitarias (2002-2003)}

Para el segundo momento, se amplía el entramado y se pone en marcha la acción de la red con el Festival Comunitario por la Vida, una iniciativa antimilitarista que dinamizó la discusión política hasta el año 2007. En sus inicios, se plantea como un evento conmemorativo de la vida y liderazgos mediante el cual las organizaciones expresaron su descontento frente a la situación de vulneración de los derechos humanos, reivindicaron la libertad y dignidad de los pobladores, y evidenciaron sus experiencias. A este carnavalesco acto de rebeldía se suman la pedagogización de los derechos humanos y el papel de la ciudadanía en su defensa, así como talleres de reflexión-formación en educación popular para los sujetos de la acción, como aporte a la construcción de subjetividades políticas (ROC, 2004; Memorias Taller Línea de Tiempo ROC, 2017).

Simultáneamente, la red se convierte en una estrategia que permitió generar cierto blindaje y protección a las organizaciones comunitarias que ante la crisis derivada de la política de seguridad democrática reciben apoyo de sus pares mediante recorridos, marchas y denuncias públicas ante amenazas. Además, se inicia un proceso de fortalecimiento de confianzas y capacidades que parte de solidaridades entre las mismas organizaciones en el que todos los saberes son importantes, el recurso financiero se colectiviza y las que contaban con mayor capacidad humana, técnica y de gestión apoyan a las "pequeñas", "y eso fue generando un hermanamiento entre las organizaciones y un posicionamiento político en la ciudad" (Entrevista personal, Pérez, 2018).

- Los lazos se afianzan y el reto se intensifica: la red en acción por la exigibilidad de los servicios públicos como un derecho fundamental (2004-2009)

En el periodo comprendido entre el 2004 y el 2009, el accionar de la ROC se torna hacia la movilización e incidencia política desde dos aristas. De un lado, propone un debate sobre la pobreza, la exclusión y la situación de desconexión de los servicios públicos domiciliarios; $y$ de otro lado, se proyectan ejercicios de planeación participativa en los procesos de ciudad. De este modo, en la agenda ya se plantea directamente la exigibilidad de derechos fundamentales y una postura de denuncia frente a los aspectos no resueltos de la modernidad con maneras de accionar desde la vida cotidiana con un fuerte trabajo de formación política comunitaria, comunicación popular alternativa, asambleas barriales y movilización callejera.

Con el lema "otra ciudad es posible, sin miseria ni exclusión" los festivales giraron en torno a la discusión de la 
situación de desconexión de los servicios públicos como un efecto del neoliberalismo. Además, el consecuente ascenso en el 2004 de un gobierno alternativo a los partidos políticos tradicionales encaminó la aparición de nuevas formas de acción social y políticas de las comunidades, como es el caso del Presupuesto Participativo, una opción del gobierno local propuesta desde abajo y que, pese a las modificaciones en la propuesta inicial, retoma experiencias de planeación del territorio y gestión del desarrollo de las comunidades.

A su vez, esta época abarca diferentes tensiones tanto internas como externas en torno a los contextos de violencia y asuntos políticos e ideológicos y el acceso-gestión de recursos que invierten las dinámicas de funcionamiento. La planeación como escenario de confrontación de diferentes poderes y lógicas se convierte en un campo de disputa entre formas de pensamiento burocráticas que permean la política formal, versus las perspectivas micro-políticas de los poderes emergentes perfectibles en la cotidianidad que privilegian la praxis. Sin embargo, los aprendizajes y potencialidades del proceso continuaron tejiendo redes de solidaridad y posibilitando luchas por el buen vivir de las comunidades.

\section{- Nuevos ciclos de vida: la ROC como escuela de diversos procesos de ciudad (2010-2015)}

De igual manera, la ROC es leída por sus integrantes, como un escenario de formación política y conciencia socio-crítica, desde el diálogo y acercamiento a los saberes, capacidades y actuaciones de los actores de otras organizaciones. Como escuela, esta articulación fortaleció proyectos institucionales de ciudad y a la par, permitió ser referente para procesos de liderazgos y organizaciones posteriores de niños-as, jóvenes y mujeres que han desempeñado roles importantes en la configuración de resistencias, reivindicaciones y colectividades en el territorio, por ejemplo, la Mesa Interbarrial de Desconectados y el Movimiento de pobladores y pobladoras. Hoy, nuevos repertorios generan importantes reflexiones en pro de la promoción y protección de los derechos humanos, la convivencia, la justicia y la transformación de significados y discursos tradicionalmente aceptados en la cultura hegemónica-patriarcal. Estos vinculan discursos y búsquedas de mayor alcance donde la recordación y la exigencia de no repetición demandan lenguajes que permitan tramitar el dolor colectivo, pero a la vez construir agendas que vinculen actores organizados en diferentes escenarios de la ciudad.

Ante las dinámicas globalizadoras e impersonales de las sociedades actuales y los contextos marcados por el conflicto, la apatía, el miedo y la frustración, la opción solidaria de un "nosotros" es la gran potencialidad de las redes, en tanto, posibilitan apoyo, identidad, intercambio, capacidades-recursos, eco de sus voces, empoderamiento y transformaciones con mayor repercusión.

\section{A modo de conclusión}

Los elementos presentados de la experiencia permiten entender la ROC como un ejercicio de ampliación del poder político posible gracias a los sujetos que logran articularse desde búsquedas colectivas que emergen del contexto de violencia en Medellín. La lucha por la vida digna y el relacionamiento desde valores como la confianza y la solidaridad constituyen una estrategia de sobrevivencia ante la constante privación de mínimos vitales como los servicios públicos y la instalación de un modelo de ciudad que excluye constantemente y reproduce territorios empobrecidos.

Las redes sociales y comunitarias en Medellín son producto del contexto de violencia y oportunidad, relacionado con la carta constitucional de 1991 y su apertura a una nueva comprensión de la participación y la ciudadanía, así como de la crisis del modelo moderno que evidencia la fractura del sistema político a través de los partidos políticos tradicionales y la necesidad de gestar nuevas formas de acción política. En este sentido, el poder contrahegemónico gestado en la ROC articula aspectos como la formación política de los sujetos vinculados, pues, como lo expresa González (2006), el contexto de violencia no solo inhibe formas de actuación, sino que también perfila otras. Las exigencias por condiciones de vida digna permiten el intercambio y la interrelación entre actores que desde el diálogo se transforman políticamente.

De igual manera el sistema valorativo que se instala desde estas interacciones, reivindica y existe desde la solidaridad, el hermanamiento y el sentido comunitario, en contraposición al sistema valorativo hegemónico que privilegia la competencia, el individualismo y las jerarquías. Este sistema adquiere existencia en forma de red, lo que posibilita la articulación estratégica de la acción colectiva en el marco político que instala el neoliberalismo. Es así como las redes sociales y comunitarias son estrategias de inclusión en un escenario de exclusiones sistemáticas que tienen como punto de partida la solidaridad, la voluntariedad y la reciprocidad y son apuestas políticas por la reconfiguración de un "nosotros" en un escenario que fragmenta lo social y privilegia el individualismo y la competencia.

En pocas palabras, el accionar político desde las redes sociales y comunitarias implican la actuación desde repertorios no convencionales como el arte, la producción de símbolos, la enunciación desde los espacios públicos y la vida cotidiana. De este modo, se resignifican elementos centrales para la incidencia pública donde se vehiculan agendas políticas y comunitarias que articulan diferentes organizaciones con independencia de la pertenencia a uno u otro territorio. Dicho estos, desde la acción de las redes se apuesta por una mirada de ciudad y de país. 


\section{Referencias}

Bal, M. (2002). Conceptos viajeros en las humanidades. Una guía de viaje. Barcelona: Ad Litteram, Cendeac.

Carballeda, A. (2002). Fragmentación, exclusión y ciudadanía: nuevos interrogantes para la intervención en lo social la intervención en lo social. En A. Carballeda. Intervención en lo social (pp. 68-95). Buenos Aires: Paidós.

Cardona, M., García, H., Giraldo, C., López, M., Suarez, C., Corcho, D. y Flórez, M. (2005). Homicidios en Medellín, Colombia, entre 1990 y 2002: actores, móviles y circunstancias. Cuadernos de Salud Pública, 21, 840-851. https://doi.org/10.1590/s0102$311 \times 2005000300018$

De Soussa, B. (2010). Descolonizar el saber, reinventar el poder. Montevideo: Ediciones Trilce.

Fernández, L y Parra, E. (2000). Participación formal y real: una mirada académica al sistema político colombiano. Reflexión Política, 2(3), 1-8.

Freire, P. (2005). Pedagogía del oprimido. Madrid: Siglo XXI Editores.

Gadamer, H. (2010). Verdad y método II. Salamanca: Ediciones Sígueme.

Gechem, S. (2009). Los partidos políticos en Colombia: entre la realidad y la ficción. Derecho del Estado, 23. 131-146
González, A. (2006). Acción colectiva en contexto de conflictividad violenta: una propuesta para su interpretación. Circunstancias, 10, 1-55.

Hidalgo, J. y Restrepo, M. (2001). Redes comunitarias locales entre la supervivencia y la emancipación. Sistematización de experiencias de red de organizaciones comunitarias en la gestión del desarrollo de la zona norte de la ciudad de Medellín. Colombia.

Kalmanovitz, S. (2001). Constitución y modelo económico. Seminario: Diez años de la Constitución colombiana, 1991-2001. Debate de evaluación. Facultad de Derecho, Universidad Nacional e ILSA. 14 y 15 de junio de 2001.

Luna, M. (2004). Redes sociales. Revista Mexicana de Sociología, 66, 59-75.

Najmanovich, D. (2001). Pensar la subjetividad. Complejidad, vínculos y emergencia. Utopía y Praxis Latinoamericana, 6(14), 106-111.

Red de Organizaciones Comunitarias. (2004). Red de Organizaciones Comunitarias de Medellín: "construyendo capacidades y tejiendo confianza”. Medellín: Coopercolt.

Reguillo, R. (2000). Emergencia de culturas juveniles. Estrategias del desencanto. Bogotá: Grupo Editorial Norma.

Simmel, G. (2014). Sociologia: estudios sobre las formas de socialización. Ciudad de México: Fondo de Cultura Económica. 